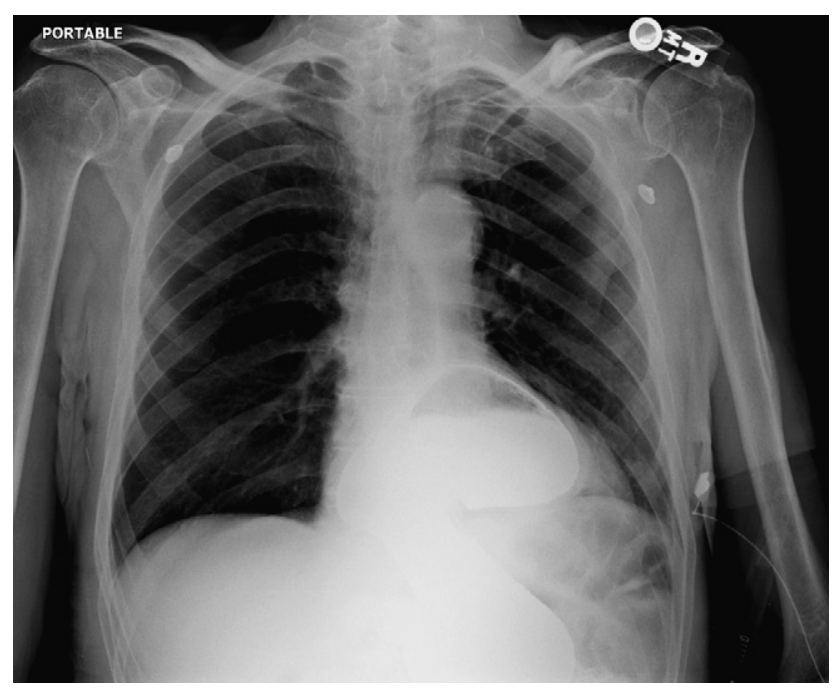

FIGURE 2. Gastrografin swallow showing thoracic hernia of the stomach.

bulge was observed in those who had concomitant intercostal muscle rupture. ${ }^{1,5}$ Plain chest radiography was the mainstay in diagnosis of diaphragmatic hernia, followed by verification with contrast studies, similar to the present report. In 2 patients, tube thoracostomy was performed for presumed pneumothorax, resulting in hollow organ injury. Except for one postmortem diagnosis, all SDRs were confirmed surgically. Nineteen $(68 \%)$ were on the left side and one was bilateral. The defects ranged from $2 \mathrm{~cm}(\mathrm{n}=2)$ to $16 \mathrm{~cm}$ in size. There were 22 $(79 \%)$ peripheral and 6 central defects. The hernia contents included stomach $(43 \%)$, colon $(29 \%)$, greater omentum
$(29 \%)$, small intestine (25\%), spleen (18\%), and liver $(10 \%)$. Ten $(36 \%)$ hernias contained a single organ, 9 (32\%) contained 2 organs, $7(25 \%)$ contained 3 organs, and the hernia contents were not specified twice. All patients who had reached the hospital alive underwent surgery. There was 1 death on admission and there were $3(14 \%)$ hospital deaths. No SRD recurrence was described. ${ }^{1-5}$

SDR can be classified into two types: a type 1 rupture, in which the chest wall remains intact, ${ }^{2,3}$ and a type 2 rupture, in which abdominal structures pass through the diaphragm and chest wall. ${ }^{1,5}$ Our review indicates that 21 (75\%) cases of SRD are type 1 and $25 \%$ are type 2 . It remains unclear to us whether a pre-existing weak spot in the diaphragm, lack of muscular coordination during intense activity, or both, might be considered in the etiology of SRD. ${ }^{1-5}$

This case and review reminds us that SRD can occur after coughing, exercise, and vaginal delivery. It is a potentially life-threatening surgical emergency requiring a high index of clinical suspicion in the right clinical setting.

\section{References}

1. Losanoff JE, Richman BW, Jones JW. Transdiaphragmatic intercostal hernia: review of the world literature. J Trauma. 2001;51:1218-9.

2. Stoica SC, Craig SR, Soon SY, Walker WS. Spontaneous rupture of the right hemidiaphragm after video-assisted lung volume reduction operation. Ann Thorac Surg. 2002;74:929-31

3. Hamoudi D, Bouderka MA, Benissa N, Harti A. Diaphragmatic rupture during labor. Int J Obstet Anesth. 2004;13:284-6.

4. Kara E, Kaya Y, Zeybek R, Coskun T, Yavuz C. A case of a diaphragmatic rupture complicated with lacerations of stomach and spleen caused by a violent cough presenting with mediastinal shift. Ann Acad Med Singapore. 2004;33:649-50.

5. Hillenbrand A, Henne-Bruns D, Wurl P. Cough induced rib fracture, rupture of the diaphragm and abdominal herniation. World J Emerg Surg. 2006;1:34.

\title{
Aneurysm expansion caused by an intercostal type II endoleak after thoracic endovascular aortic repair for secondary elephant trunk graft fixation
}

\author{
Atsushi Kitagawa, MD, Hitoshi Matsuda, MD, Kenji Okada, MD, and Yutaka Okita, MD, Kobe, Japan
}

From the Division of Cardiovascular Surgery, Department of Surgery, Kobe University Graduate School of Medicine, Kobe, Japan

Disclosures: None.

Received for publication March 25, 2009; accepted for publication June 10, 2009; available ahead of print July 30, 2009.

Address for reprints: Yutaka Okita, MD, Division of Cardiovascular Surgery, Department of Surgery, Kobe University Graduate School of Medicine, 7-5-2 Kusunokicho, Chuo-ku, Kobe 650-0017, Japan (E-mail: yokita@med.kobe-u.ac.jp).

J Thorac Cardiovasc Surg 2010;139:e128-30

$0022-5223 / \$ 36.00$

Copyright (c) 2010 by The American Association for Thoracic Surgery

doi:10.1016/j.jtcvs.2009.06.011
Although the majority of intercostal type II endoleaks, retrograde aortic branch flows into the aneurysm sac, after thoracic endovascular aortic repair (TEVAR) of a descending thoracic aortic aneurysm generally resolve without any reintervention, ${ }^{1,2}$ we report a rare case of aneurysm expansion caused by an intercostal type II endoleak 7 years after TEVAR for secondary elephant trunk graft (ETG) fixation.

\section{CLINICAL SUMMARY}

In 1994, a 60-year-old man had an ETG inserted for an aortic arch aneurysm, followed by fixation of the ETG via 

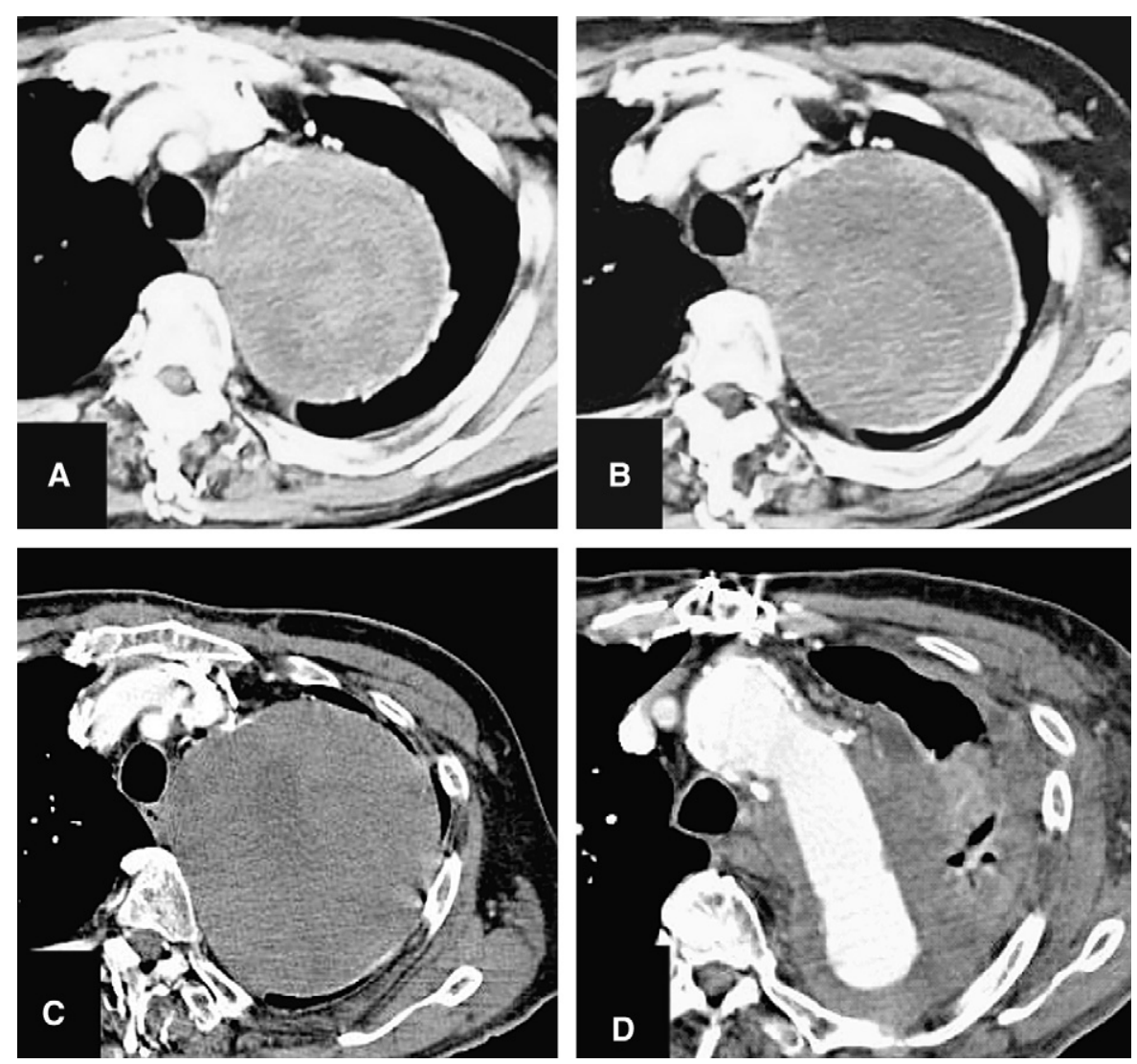

FIGURE 1. Computed tomography scans of descending thoracic aortic aneurysm: $83 \mathrm{~mm}$ in 2001 (A), $97 \mathrm{~mm}$ in 2004 (B), $110 \mathrm{~mm}$ in 2008 (C), and after graft replacement of the descending thoracic aorta (D).

a left thoracotomy in 2000. In 2001, he was referred to the Kobe University Graduate School of Medicine because the aneurysm expanded (83 $\mathrm{mm}$ in diameter) (Figures 1 and 2).

TEVAR, using a 34- $\times 75$-mm (diameter by length) homemade endoprosthesis composed of a Gianturco Z-stent (Cook, Bloomington, Ind) with a UBE polyester Dacron graft (Junken Medical, Tokyo, Japan), was performed to cover both the distal ETG end and the expanded aneurysm. However, the aneurysm continued to grow up to $97 \mathrm{~mm}$ in 2004. Angiogram showed the type II endoleak from the fourth intercostal artery, which was treated by a coil embolization via the left internal thoracic artery using the left brachial artery approach. Although no type II endoleaks were found on multislice computed tomography, the aneurysm expanded again up to $110 \mathrm{~mm}$ in diameter.

In 2008, the angiogram showed recurrence of an intercostal type II endoleak supplied by the left internal thoracic artery and the left costocervical trunk (Figure 3). We performed a graft replacement of the descending thoracic aorta and closure of the type II endoleakage via a left thoracotomy under partial cardiopulmonary bypass despite the severe adhesion of the patient's lung as a result of the previous thoracotomy. The patient was discharged on the 14th postoper- ative day uneventfully and is still well without any aortic event during the 1-year follow-up.

\section{DISCUSSION}

Intercostal type II endoleaks are not uncommon after TEVAR for a descending thoracic aortic aneurysm. Although

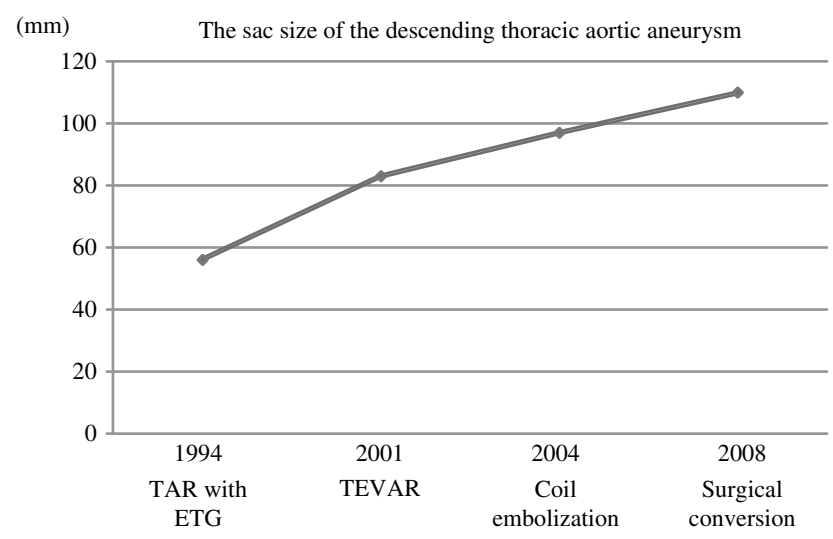

FIGURE 2. Sac size of the descending thoracic aortic aneurysm by year. $T A R$, Total arch replacement; ETG, elephant trunk graft; TEVAR, thoracic endovascular aortic repair. 

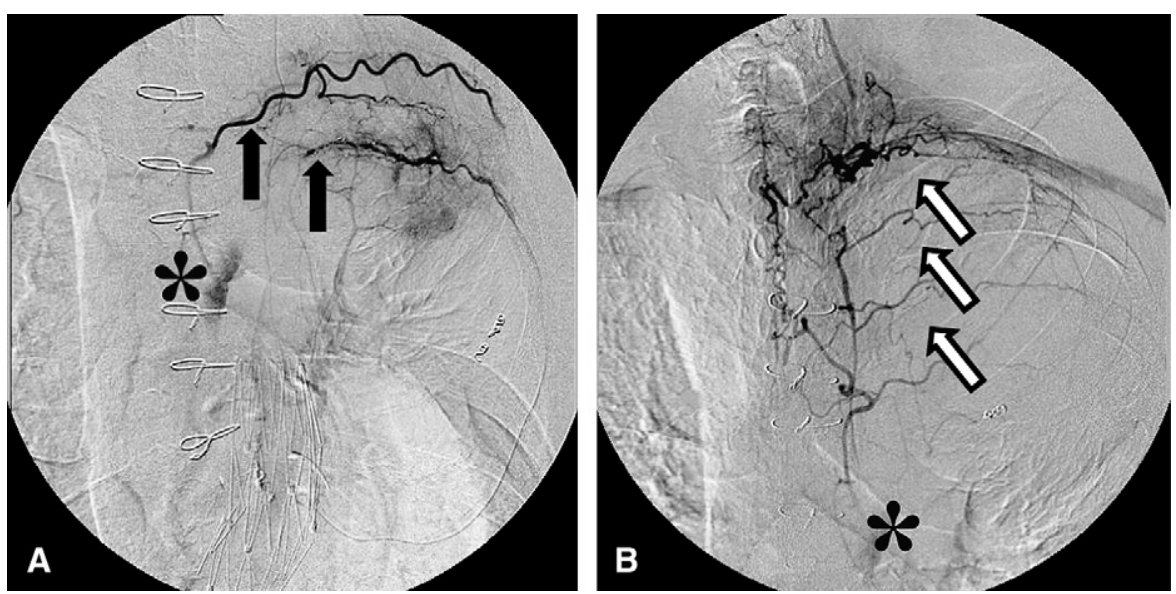

FIGURE 3. Angiogram in 2008 showed recurrence of intercostal type II endoleak (*), which was supplied by the (A) left internal thoracic artery (black arrow) and (B) left costocervical trunk (white arrow).

they do occur, most of them are thrombosed naturally without any intervention. ${ }^{1,2}$ However, Parmer and colleagues ${ }^{3}$ previously reported an association between intercostal type II endoleaks and continued sac expansion after TEVAR. The maximum aneurysm diameter caused by intercostal type II endoleaks after TEVAR increased by $2.94 \pm 7.2 \mathrm{~mm}$ without secondary intervention during a follow-up of $17.3 \pm 14.7$ months. ${ }^{3}$ In the present case, we finally performed an open conversion for persistent aneurysm expansion after TEVAR despite the additional coil embolization throughout the 7-year follow-up. Other treatment options, such as thoracoscopic ligation of a leak, are not reported in the literature, except for laparoscopic ligation of an inferior mesenteric artery documented by Richardson and colleagues ${ }^{4}$ as a treatment option for a type II endoleak after endografting for an abdominal aortic aneurysm. Although open conversion for continued sac expansion caused by intercostal type II endoleaks is rare, Preventza and colleagues $^{2}$ documented a single case of open conversion for aneurysm rupture attributed to intercostal type II endoleaks in 246 TEVAR cases.

Morales and colleagues ${ }^{1}$ showed an association between intercostal type II endoleaks and previous aortic surgery with ETG placement; however, a correlation between intercostal type II endoleaks and ETG insertion is still unclear.

\section{CONCLUSIONS}

Intercostal type II endoleaks after TEVAR have the potential to cause persistent sac expansion regardless of coil embolization and should be monitored closely over the long-term follow-up.

\section{References}

1. Morales JP, Greenberg RK, Lu Q, Cury M, Hernandez AV, Mohabbat W, et al. Endoleaks following endovascular repair of thoracic aortic aneurysm: etiology and outcomes. J Endovasc Ther. 2008;15:631-8.

2. Preventza O, Wheatley GH 3rd, Ramaiah VG, Rodriguez-Lopez JA, Williams J, Olsen D, et al. Management of endoleaks associated with endovascular treatment of descending thoracic aortic diseases. J Vasc Surg. 2008;48:69-73.

3. Parmer SS, Carpenter JP, Stavropoulos W, Fairman RM, Pochettino A, Woo EY, et al. Endoleaks after endovascular repair of thoracic aortic aneurysms. J Vasc Surg. 2006;44:447-52.

4. Richardson WS. Sternbergh WC 3rd, Money SR. Laparoscopic inferior mesenteric artery ligation: an alternative for the treatment of type II endoleaks. J Laparoendosc Adv Surg Tech A. 2003;13:355-8. 